\title{
Smokers' perceptions of different classes of cigarette brand descriptors
}

\author{
Nicholas J. Felicione', Kaila J. Norton', Maansi Bansal-Travers', Vaughan W. Rees ${ }^{3}$, K. Michael Cummings ${ }^{4}$, Richard J. \\ $\mathrm{O}^{\prime} \mathrm{Connor}^{\mathrm{T}}$
}

\begin{abstract}
INTRODUCTION Cigarette brand descriptors such as 'light' are banned in several countries and often replaced by alternative descriptors that continue to mislead smokers about the relative risk from those brands. The objective of this study was to evaluate perceptions from current brand descriptors when presented independently of cigarette packaging.

METHODS Eighty-eight daily cigarette smokers attended semi-structured interviews at three US research laboratories in 2018-2019 to assess smokers' perceptions of cigarette brand descriptors in four classes of brand features: prestige, connotation, taste, and color. Participants ranked descriptors within each brand feature on perceived harm, attractiveness, and appeal (willingness to try). Ranked perceptions were described using median rankings and percentages. Chi-squared was used to assess demographic effects on perceptions. Spearman's correlation was used to assess the association between harm, attractiveness, and appeal rankings.

RESULTS Brand descriptors influenced perceptions of harm, attractiveness, and appeal within each brand feature. Smooth was perceived as the most attractive (42.5\%) and appealing (33.0\%) taste descriptor. Red was perceived as the most harmful $(45.4 \%)$ and least appealing $(22.7 \%)$ color descriptor. Perceptions of certain descriptors differed by demographic characteristics such as sex and age. Rankings of attractiveness and appeal were more strongly correlated $(\mathrm{r}=0.63)$ than rankings of harm and appeal $(\mathrm{r}=0.20, \mathrm{p}<0.01)$.

ConcLusions Cigarette manufacturers replaced banned descriptors with alternative descriptors that continue to influence perceptions of cigarettes. Regulatory agencies should closely evaluate all brand descriptors and consider implications for alternative products with fewer regulations.
\end{abstract}

\section{AFFILIATION}

1 Department of Health Behavior, Roswell Park Comprehensive Cancer Center, Buffalo, United States 2 The Ohio State University Comprehensive Cancer Center, Columbus, United States 3 Department of Social and Behavioral Sciences, Harvard T.H. Chan School of Public Health, Boston, United States 4 Department of Psychiatry and Behavioral Sciences, Medical University of South Carolina, Charleston, United States

CORRESPONDENCE TO Nicholas J. Felicione. Department of Health Behavior, Roswell Park Comprehensive Cancer Center, 665 Elm St, Buffalo, NY 14216, United States. E-mail: nicholas.felicione@ roswellpark.org

\section{KEYWORDS}

tobacco, packaging, perceptions, cigarette, brand descriptors

Received: 20 August 2020

Revised: 24 November 2020

Accepted: 7 December 2020

\section{INTRODUCTION}

Cigarette manufacturers use brand names and descriptors to communicate characteristics of their products, such as sensory features and nicotine delivery ${ }^{1,2}$. Compared to plain packs, packs carrying descriptors and brand imagery are perceived as having a smoother taste, better quality, delivering more tar, more attractive, and more appealing to youth $^{3-6}$. Many government agencies, including the
U.S. Food and Drug Administration (FDA), have restricted certain descriptors such as 'low', 'light', and 'mild', in part due to their potential to mislead consumers about the health risks of associated brands, despite no association with reduced health risk $^{7,8}$. However, misperceptions of the health risks of 'light' cigarettes continue ${ }^{3,9-13}$. This may be due to the use of colors, numbers, or other descriptors replacing these targeted terms and a possible lack of smokers noticing 
changes to their packs after the removal of the specific descriptors ${ }^{14-18}$. Notably, the ban on 'light' descriptors has not affected uptake, use, or the market share of 'light' cigarettes ${ }^{14}$, likely due to the substitution of color descriptors.

Pack color, design, and descriptor term influence perceptions of risk and intentions to use $\mathrm{u}^{3,4,15,19,20}$. For instance, smokers reported different tastes when smoking identical cigarettes that were presented in different cigarette packs ${ }^{21}$. In some cases, cigarette manufacturers removed restricted terms and replaced them with color descriptors, often colors that were already associated with the sub-brand (e.g. Marlboro Light became Gold) ${ }^{16}$. Pairing these new descriptors with specific product characteristics (e.g. filter ventilation) led to smokers continuing to consider cigarette brands as 'light' or 'mild'3,10,12,13. Colors also have functions in marketing with respect to sensory perceptions ${ }^{22}$. More white space and lighter colors reduced perceptions of strength ${ }^{23}$, and Marlboro cigarettes in red packs were perceived as harsher than in blue packs ${ }^{24}$.

In addition to colors, other brand descriptors such as 'smooth' remain on cigarette packs. As with colors, these alternative descriptors continue the misperception of lower harm of certain cigarette brands, particularly among adolescents and young adults $^{4,5}$. In adult smokers, descriptors such as 'smooth' are perceived as delivering less tar, having a smoother taste, and having lower health risk compared to packs labeled as 'full flavor's. Today, smokers increasingly rely on pack colors and other descriptors to determine product features and identify preferred cigarette brands ${ }^{11}$.

In marketing, branding defines how a product is intended to be perceived. A brand uses a unique design, sign, symbol, word, or a combination of these, to attempt to create an image that identifies a product and differentiates it from its competitors. Branding is a core component in increasing the appeal of a tobacco product. Appeal for tobacco products can be conceptualized as willingness to try a product that is mediated by other factors such as abuse liability (e.g. delivery of nicotine, sensory effects, and taste) and consumer perception (e.g. knowledge, beliefs, social influence $)^{25}$.

There is growing evidence that product harm perceptions are associated with different product descriptor terms and packaging colors $3,11,12,15,20,26$. However, research is needed to evaluate how specific descriptors and colors affect consumer perceptions of product harm and appeal. This is particularly important in the US context where the law mandates that FDA regulates the marketing of tobacco products so that consumers are not misled ${ }^{27}$.

The current study examines how product descriptors influence consumers' perceptions of cigarettes, using four classes of brand descriptors as suggested by Hoek et al. $\left.{ }^{26}: 1\right)$ prestige, which defines a brand's status, 2) connotation (which attempts to portray a brand image), 3) taste, and 4) color. Within each of these categories, we examined how different product descriptors ranked with respect to attractiveness, harmfulness, and appeal.

\section{METHODS}

\section{Participants}

Eighty-eight participants completed the study at three sites:

Roswell Park Comprehensive Cancer Center (Buffalo, NY; $n=39$ ),

Harvard Chan School of Public Health (Boston, MA; $\mathrm{n}=20$ ),

and Medical University of South Carolina (Charleston, SC; $n=29)$.

Participants were recruited from May 2018 to July 2019 via local newspapers, websites, and social media platforms. Inclusion criteria were: 1) aged 18-39 years (21 in Boston due to minimum age of purchase laws), 2) smoke $\geq 5$ factory-made filtered cigarettes/day for $\geq 1$ year, 3 ) 'fair' or better selfrated physical and mental health, and 4) Englishspeaking. Exclusion criteria were: 1) active cessation efforts or plans to quit in next 30 days, 2) regular use of other nicotine products, 3 ) past year binge drinking or illegal drug use, and 4) pregnancy. Data were collected regarding participant demographics, tobacco use history, nicotine dependence (FTCD: Fagerström Test for Cigarette Dependence) ${ }^{28}$ and behavioral aspects of cigarette dependence (GN: Glover-Nilsson Scale $)^{29}$. All participants provided informed consent and participant confidentiality was maintained.

\section{Design}

We evaluated brand descriptors within four classes of 
Table 1. Descriptors used within each four cigarette brand features

\begin{tabular}{cllll}
\hline \multirow{2}{*}{ Descriptors } & Prestige & Connotation & \multicolumn{1}{c}{ Taste } & \multicolumn{1}{c}{ Color } \\
& Premium & Classic & Rich & Red \\
Special & Midnight & Smooth & Gold \\
Distinct & Infinite & Fine & Silver \\
Reserve & Unique & Mellow & Blue \\
Real & Balanced & Refined & Orange \\
& & Ultra & Bold & White \\
& Super & Robust & Black \\
& Bright & Full-bodied & Turquoise \\
& & Full flavor & Pink \\
& & & Purple
\end{tabular}

brand features: prestige (i.e. brand status), connotation (i.e. brand image), taste, and color (see Table 1 for descriptors within each class). The primary dependent variables were rankings of harm, attractiveness, and appeal (defined as willingness to try) perceptions of descriptors within each brand feature. Rankings of harm and attractiveness were intended to reflect perceived product characteristics, while appeal was intended to reflect behavioral intentions (i.e. likely to try).

\section{Procedure}

Participants attended one in-person semi-structured interview that lasted 45 minutes. An interviewer at each site followed a standardized discussion guide to ensure consistency across sites. Each interview included discussions about cigarettes in general, and questions designed to address product awareness, reasons for use, risk perceptions, and perceptions about marketing. The interviewers then pursued a more in-depth conversation to elicit perceptions surrounding brand descriptors and colors. Finally, participants engaged in a task to rank the perceived harm, attractiveness, and appeal of each descriptor within each brand feature. For example, the five prestige descriptors were ranked from 1 to 5 for harm, attractiveness, and appeal separately. This process was repeated for the taste, connotation, and color descriptors. Descriptors were presented to participants in a randomized order. All procedures were approved by the Roswell Park Comprehensive Cancer Center Institutional Review Board.

\section{Data analysis}

Participant demographics and smoking history were assessed with descriptive analyses and were compared across study sites using chi-squared test and one-way ANOVA. Data from the three sites were pooled for further analyses to increase sample diversity, given that all sites are in the same cigarette market (e.g. same labelling rules). The independent variables in the study were the brand descriptors, analyzed separately for each brand feature (i.e. prestige, taste, connotation, color). The primary dependent variables analyzed in the current study were the ranked perceptions of harm, attractiveness, and appeal. Perceptions of appeal and attractiveness were reverse coded such that higher ranks indicated more positive consumer perceptions (i.e. lower harm, greater appeal, more attractive). Descriptive analyses were used to generate radar plots that depict median rankings for each descriptor and stacked bar charts showing the per cent of participants that ranked descriptors as the most/least harmful, attractive, or appealing. Additionally, chi-squared was used to assess for demographic differences in descriptor rankings $(p<0.01)$. These analyses were considered exploratory and a stricter $\mathrm{p}$ value $(0.01)$ was used in place of more formal adjustments. Demographic factors included age (median split: 19-32, $\geq 33$ ), sex (male, female), race (White, NonWhite), education ( $\leq$ high school diploma, some college + ), and nicotine dependence (low: FTCD $\geq 4$, moderate-high: FTCD $\geq 5$ ). Spearman's correlations $(p<0.05)$ were used to assess the correlation between rankings of harm, appeal, and attractive within each descriptor category individually (i.e. separate analyses for prestige, connotation, taste, color) and across all descriptor categories (i.e. all descriptors combined).

\section{RESULTS}

\section{Participant demographics}

Table 2 gives demographic characteristics and tobacco use history among the full sample and by study site. Participants at each study site did not differ on smoking characteristics such as cigarettes/day, years smoking usual brand, FTCD scores, or GN scores (all $\mathrm{F}<2.68, \mathrm{p}>0.05$ ), though they did differ on age, race, education, and income (all $\mathrm{p}<0.05$ ).

\section{Rankings of descriptors}

Radar plots demonstrating the aggregated median 
Table 2. Participant demographic and smoking characteristics

\begin{tabular}{|c|c|c|c|c|c|c|}
\hline Characteristics & $\begin{array}{c}\text { Boston } \\
(n=20) \\
M(S D) \text { or \% }\end{array}$ & $\begin{array}{c}\text { Buffalo } \\
(n=39) \\
M(S D) \text { or \% }\end{array}$ & $\begin{array}{l}\text { Charleston } \\
\quad(n=29) \\
M(\text { SD) or \% }\end{array}$ & $\begin{array}{l}\text { Full sample } \\
\begin{array}{l}(\mathbf{N}=88) \\
M(\mathrm{SD}) \text { or } \%\end{array}\end{array}$ & F or $\chi^{2}$ & $p$ \\
\hline Age (years) & $33.60(5.40)$ & $32.46(5.02)$ & $29.17(5.72)$ & 31.64 (5.58) & & 0.01 \\
\hline $19-32$ & 45.0 & 35.9 & 72.4 & 50.0 & & \\
\hline$\geq 33$ & 55.0 & 64.1 & 27.6 & 50.0 & & \\
\hline Non-Hispanic & 70.0 & 89.7 & 93.1 & 86.4 & 7.61 & $>0.05$ \\
\hline White & 45.0 & 79.5 & 58.6 & 64.8 & 7.61 & $<0.05$ \\
\hline Female & 45.0 & 69.2 & 62.1 & 61.4 & 3.28 & $>0.05$ \\
\hline Some college+ & 90.0 & 61.5 & 41.4 & 61.4 & 11.80 & $<0.01$ \\
\hline Income category (US\$) & & & & & 15.79 & $<0.05$ \\
\hline$<25000$ & 35.0 & 35.9 & 24.5 & 35.2 & & \\
\hline 25000-49999 & 15.0 & 30.8 & 37.9 & 29.5 & & \\
\hline$\geq 50000$ & 45.0 & 30.8 & 6.9 & 26.1 & & \\
\hline Prefer not to say & 5.0 & 2.6 & 20.7 & 9.1 & & \\
\hline Cigarettes/day & $9.20(4.56)$ & $11.13(5.44)$ & $13.97(10.40)$ & $11.62(7.46)$ & 2.67 & $>0.05$ \\
\hline Years smoking usual brand & $7.53(5.93)$ & $8.69(5.87)$ & $8.59(6.31)$ & $8.39(5.98)$ & 0.27 & $>0.05$ \\
\hline FTCD score & $3.90(1.89)$ & $3.36(2.21)$ & $4.45(2.08)$ & $3.84(2.12)$ & 2.25 & $>0.05$ \\
\hline GN score & $22.17(6.50)$ & 18.49 (6.37) & 20.85 (6.64) & 20.04 (6.59) & 2.30 & $>0.05$ \\
\hline
\end{tabular}

FTCD range $0-10$, with scores $\geq 4$ indicating low dependence. GN range $0-44$.

rankings of harm, attractiveness, and appeal for prestige, least harmful, attractive, and appealing descriptors based taste, connotation, and color descriptors are displayed in Figure 1. Figure 2 summarizes findings in four stacked bar charts which display the percentage of participants that ranked each descriptor as the most or least harmful, on median and per cent ranking.

\section{Prestige}

Visual inspection of the radar plots shown in Figure attractive, and appealing. Table 3 summarizes the most/ 1 suggests that median rankings of a product's harm,

Figure 1. Radar plots demonstrating the aggregated median rankings of harm, attractiveness, and appeal for prestige, taste, connotation, and color descriptors
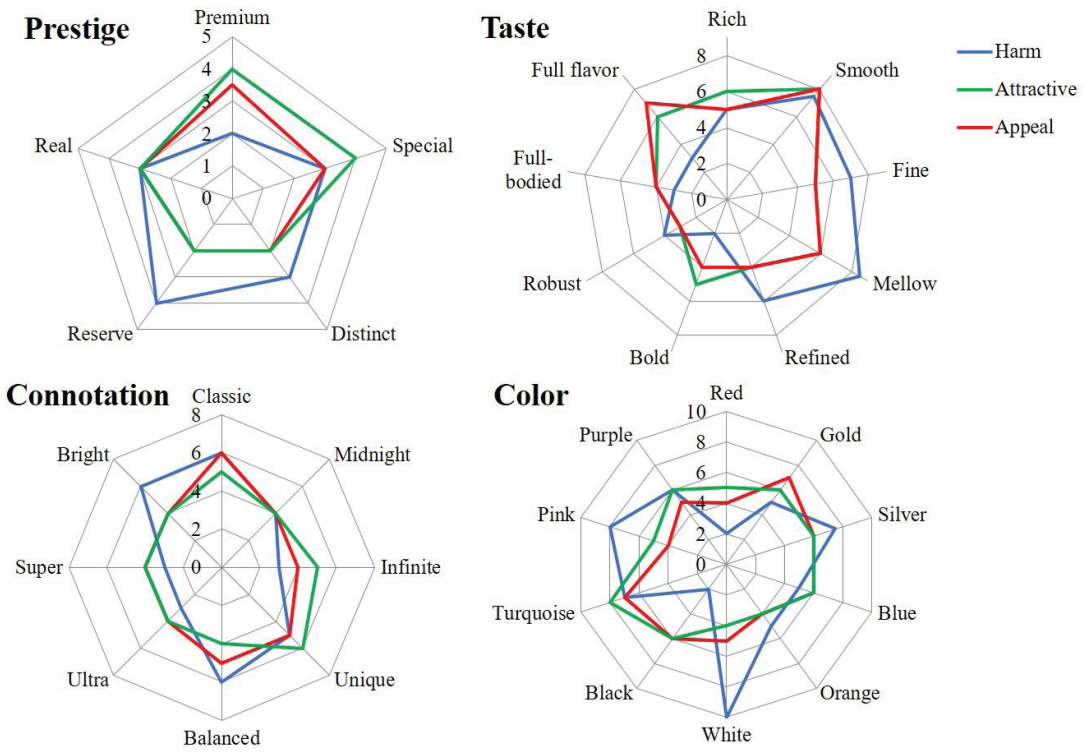
Figure 2. Stacked bar charts which display the percentage of participants that ranked each descriptor as the most or least harmful, attractive, and appealing
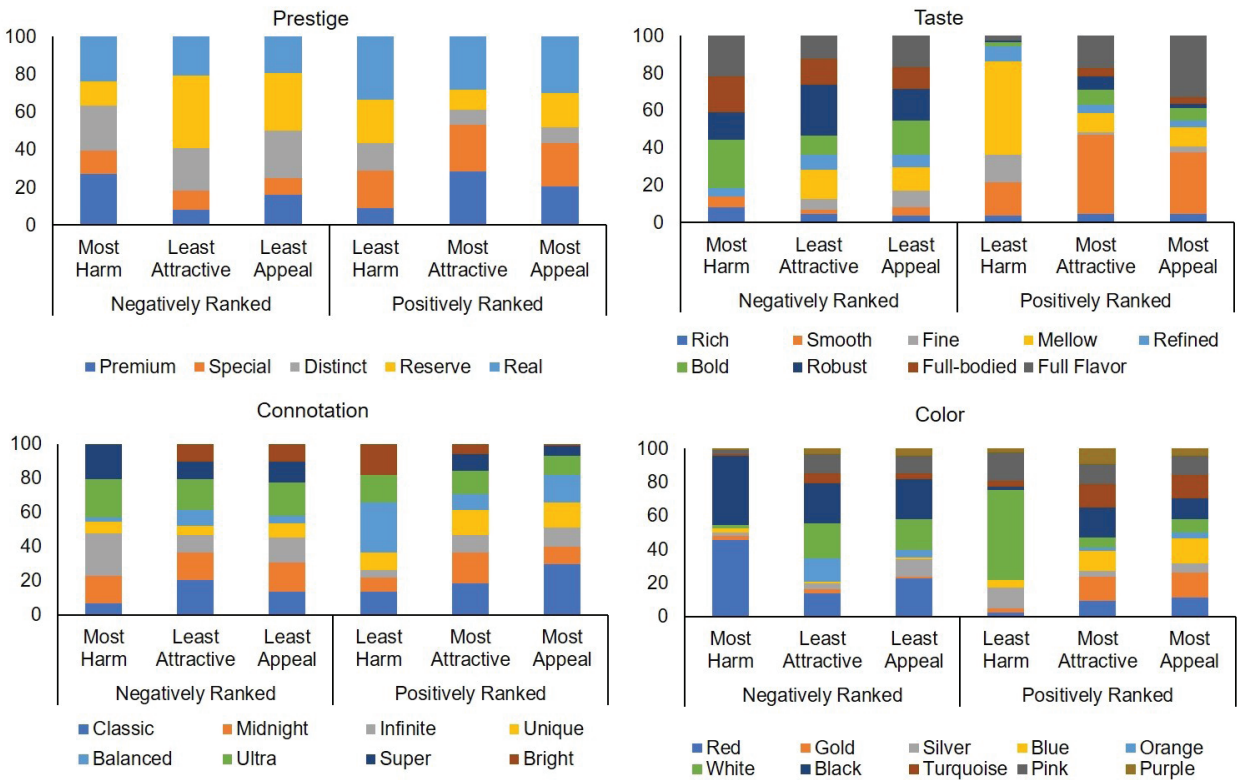

attractiveness, and appeal were most similar for three descriptor labels: Real, Special, and Distinct. Rankings diverged most for two descriptors: Premium and Reserve. For example, median rankings of harm were higher (less harmful) for Reserve compared to rankings of attractiveness and appeal, while the

opposite was observed for Premium. As summarized in Table 3, median rankings of attractiveness overlapped with rankings of appeal more than rankings of harm and appeal.

Median rankings of harm for prestige descriptors ranged 2-4. Median rankings indicated that Reserve

Table 3. Least/most harmful, attractive, and appealing descriptors based on median rankings and percentage of participant rankings

\begin{tabular}{|c|c|c|c|c|c|c|c|c|}
\hline \multirow[b]{2}{*}{ Domain } & \multicolumn{2}{|c|}{ Prestige } & \multicolumn{2}{|c|}{ Taste } & \multicolumn{2}{|c|}{ Connotation } & \multicolumn{2}{|c|}{ Color } \\
\hline & Largest \% & Median & Largest \% & Median & Largest \% & Median & Largest \% & Median \\
\hline Least harmful & Real & Reserve & Mellow & Mellow & Balanced & $\begin{array}{l}\text { Classic, } \\
\text { Balanced, } \\
\text { Bright }\end{array}$ & White & White \\
\hline Most harmful & Premium & Premium & Bold & Bold & Ultra & $\begin{array}{l}\text { Infinite, } \\
\text { Ultra, Super }\end{array}$ & Red & Red, Black \\
\hline Most attractive & $\begin{array}{l}\text { Real, } \\
\text { Premium }\end{array}$ & $\begin{array}{l}\text { Special, } \\
\text { Premium }\end{array}$ & Smooth & Smooth & $\begin{array}{l}\text { Classic, } \\
\text { Midnight }\end{array}$ & Unique & Black & Turquoise \\
\hline Least attractive & Reserve & $\begin{array}{l}\text { Reserve, } \\
\text { Distinct }\end{array}$ & Robust & Robust & Balanced & $\begin{array}{l}\text { Midnight, } \\
\text { Ultra, } \\
\text { Balanced, } \\
\text { Super, Bright }\end{array}$ & Black & $\begin{array}{l}\text { Orange, } \\
\text { White }\end{array}$ \\
\hline Most appealing & Real & Premium & $\begin{array}{l}\text { Smooth, Full } \\
\text { flavor }\end{array}$ & Smooth & Classic & Classic & Gold, Blue & $\begin{array}{l}\text { Gold, } \\
\text { Turquoise }\end{array}$ \\
\hline Least appealing & Reserve & $\begin{array}{l}\text { Distinct, } \\
\text { Reserve }\end{array}$ & Bold & Robust & Ultra & $\begin{array}{l}\text { Midnight, } \\
\text { Infinite, } \\
\text { Ultra, Super, } \\
\text { Bright }\end{array}$ & Black & $\begin{array}{l}\text { Red, Orange, } \\
\text { Pink }\end{array}$ \\
\hline
\end{tabular}


was perceived as least harmful (i.e. highest ranking) and Premium was perceived as most harmful (i.e. lowest ranking) (Figure 1 and Table 3 ). This finding is consistent with the $27.2 \%$ of participants ranking Premium as most harmful and $9.2 \%$ ranking it least harmful. Real was ranked least harmful by more participants than other prestige descriptors (33.3\%), despite lower median rankings than Reserve. Reserve and Special were ranked as most harmful by fewer participants (12.5\%) than other prestige descriptors.

The range of median rankings of attractiveness was 2-4 across prestige descriptors (Figure 1 and Table 3). Rankings of attractiveness were highest for two descriptors: Special and Premium, and lowest for Reserve and Distinct. Premium and Real were ranked most attractive by more participants than any other descriptor. Premium and Special were ranked least attractive by fewer participants than other descriptors (8.0\% and $10.2 \%$, respectively). Reserve was ranked least attractive by the most participants (38.6\%) and ranked most attractive by only $8.0 \%$ of participants.

The range of median rankings for appeal was 2-3.5 across prestige descriptors. Median rankings of appeal (willingness to try) were highest for Premium and lowest for descriptors Distinct and Reserve (Figure 1 and Table 3 ). Real was ranked by the most participants as most appealing (29.9\%), followed by Special (23.0\%). Special was also ranked least appealing by the fewest participants (9.1\%). Reserve was most ranked least appealing by the most participants (30.7\%), followed by Distinct (25.0\%).

\section{Taste}

The radar plot for taste shows more variation in median rankings within descriptors than was observed for prestige descriptor labels (Figure 1). Similar median rankings of harm, attractiveness, and appeal were observed within the descriptors Smooth, Robust, Rich, and Full-bodied. Fine, Mellow, Refined, and Robust were ranked less harmful (higher median) compared to their median rankings of attractiveness and appeal. Full flavor, Full-bodied, and Bold were ranked more harmful than their rankings on attractiveness and appeal. Overall, aggregated median rankings of attractive and appeal are more consistent with each other than with rankings of harm.
Median rankings of taste descriptors on harm had a wide range of scores from 2 to 8.5. Median rankings indicated that Mellow was perceived as least harmful and Bold as most harmful (Figure 1 and Table 3). Mellow was never ranked most harmful and was ranked least harmful by $50.0 \%$ of participants; whereas Bold was ranked most harmful by $26.1 \%$ and least harmful by only $2.3 \%$ of participants. No participants ranked Full-bodied as least harmful and no participants ranked Fine or Mellow as most harmful.

Median rankings of descriptors on attractiveness also had a wide range of scores from 3 to 8 . Median rankings of attractiveness were highest for Smooth and lowest for Robust (Figure 1 and Table 3 ). Smooth was ranked most attractive by $42.5 \%$ and least attractive by only $2.3 \%$ of participants. By contrast, Robust was ranked least attractive by $27.3 \%$ of participants. Taste descriptors such as Rich, Fine, Refined, and Bold were rarely ranked as most or least attractive.

Like attractiveness, median rankings of descriptors on appeal ranged from 3 to 8 , with Smooth ranked as most appealing and Robust ranked as least appealing (Figure 1 and Table 3). Smooth was ranked most appealing by $33.0 \%$ of participants, and least appealing by only $3.4 \%$ of participants. Full flavor was ranked most appealing by $33.0 \%$ of participants, but also least appealing by the second highest number of participants $(17.0 \%)$. Robust was ranked most appealing by the fewest participants $(2.3 \%)$.

\section{Connotation}

Though there is notable variation in median rankings of harm, attractiveness, and appeal within some connotation descriptors, the range of scores is not as large as observed for taste descriptors (Figure 1). For example, median rankings of harm for Bright and Balanced were higher (less harmful) than attractiveness and appeal, though this difference was only one to two ranking positions. The opposite pattern of results was observed for Super, Infinite, and Ultra.

Median rankings of harm for connotation descriptors had a narrower range than in the taste category, range 3-6. Median rankings indicated that Balanced, Bright, and Classic were perceived as least harmful, while Super, Ultra, and Infinite were perceived as most harmful (Figure 1 and Table 3). Twenty-nine per 
cent of participants ranked Balanced as least harmful and only $2.3 \%$ as most harmful. No participant ranked Super as least harmful or Bright as most harmful.

Median rankings of attractiveness for connotation descriptors were narrower than for harm rankings, range 4-6. Median rankings for attractiveness showed that Unique was ranked most attractive while Ultra, Midnight, Balanced, Super, and Bright were ranked least attractive (Figure 1 and Table $3)$. This result is consistent with highest and lowest ranking frequencies, in which no descriptor was rated as most or least attractive by more than $20.5 \%$ of participants. Some descriptors had comparable number of participants ranking them as least and most attractive such as Classic (10.2\%), Infinite (10.2\%), and Balanced (9.1\%).

Median rankings of connotation descriptors on appeal follow the same pattern as attractiveness rankings, with a narrow range of scores from 4 to 6. Classic had the highest median appeal ranking while Bright, Super, Ultra, Infinite, and Midnight were ranked least appealing (Figure 1 and Table 3 ). Classic was the only descriptor ranked as most appealing by $>20 \%$ of participants, $29.5 \%$ rated Classic as most appealing. Bright scored lowest on appeal by participants, ranked as most appealing by only $1.1 \%$ of participants.

\section{Color}

The discrepancies between mean rankings of harm, attractiveness, and appeal seem larger for color than other brand features based on inspection of the radar plot (Figure 1). Still, some descriptors show converging results for all three outcomes (e.g. Turquoise, Purple). Generally, rankings of attractiveness and appeal were more similar than rankings of harmfulness. Rankings of harm substantially diverged from attractiveness and appeal for Red, White, Black, and Pink.

Median rankings of harm for color descriptors had a wide range of scores from 2 to 10. Median rankings demonstrated that White was ranked least harmful, the colors Red and Black were ranked most harmful (Figure 1 and Table 3). Red and Black were ranked most harmful by the largest proportion of participants ( $45.4 \%$ and $40.9 \%$, respectively), while all other color descriptors were ranked most harmful by $<3 \%$ of participants. Orange was never ranked as most or least harmful. White was ranked as least harmful by $53.4 \%$ of participants, which was the largest percentage of any ranking across all descriptors.

Median rankings of color descriptors on attractiveness had a narrower range compared to harm rankings, range 4-8. Turquoise had the highest median attractiveness ranking, Orange and White were ranked as least attractive (Figure 1 and Table 3). However, no color descriptors were ranked most attractive by many participants. More variation was observed in least attractive rankings, with the colors Black and White most commonly ranked least attractive $(24.1 \%$ and $20.7 \%$, respectively). In contrast, Blue was ranked least attractive by only $1.1 \%$ of participants.

Median rankings of color descriptors on appeal ranged 4-7. Turquoise and Gold had the highest median appeal rankings. Orange, Red, and Pink were ranked least appealing (Figure 1 and Table 3 ). There was no color descriptor that was consistently ranked as most attractive (range: $3.4-14.8 \%$ ). By contrast, Black and Red were most often nominated as least appealing ( $23.9 \%$ and $22.7 \%$, respectively). Blue and Gold were nominated as least appealing by only $1.1 \%$ of participants.

\section{Correlation between harm, appeal, and attractiveness}

Among all descriptors combined, rankings on harm were weakly correlated with appeal $[\mathrm{r}(2805)=0.20]$ and attractiveness $[\mathrm{r}(2791)=0.17, \mathrm{p}<0.001]$, i.e. lower harm rankings were associated with higher rankings for appeal and attractiveness. Appeal and attractiveness rankings also were strongly correlated $[r(2789)=0.63, p<0.001]$.

Among prestige descriptors, harm was positively correlated with appeal $[\mathrm{r}(435)=0.25, \mathrm{p}<0.001]$ but not attractiveness $[\mathrm{r}(436)=0.09, \mathrm{p}>0.05]$. Additionally, appeal and attractiveness were correlated $[\mathrm{r}(435)=0.53, \mathrm{p}<0.001]$. Among taste descriptors, harm was weakly associated with appeal $[\mathrm{r}(786)=0.13]$ and attractiveness $[\mathrm{r}(785)=0.15]$; appeal and attractiveness were strongly correlated $[\mathrm{r}(783)=0.66$, $\mathrm{p}<0.001]$. Among connotation descriptors, harm was weakly correlated with appeal $[\mathrm{r}(700)=0.12, \mathrm{p}<0.001]$ but not attractiveness $[\mathrm{r}(699)=0.03, \mathrm{p}>0.05]$, appeal and attractiveness were moderately associated $[\mathrm{r}(699)=0.47, \mathrm{p}<0.001]$. Among color descriptors, harm was not correlated with appeal $[\mathrm{r}(877)=0.06]$ or attractiveness $[\mathrm{r}(865)=0.05, \mathrm{p}>0.05]$, however, 
appeal and attractiveness were strongly correlated $[\mathrm{r}(866)=0.62, \mathrm{p}<0.001]$.

\section{Interactions with demographics} Age

Age effects were observed for Midnight (connotation), with $25 \%$ of older participants ranking Midnight as most harmful (59.1\% top 3), compared to $6.8 \%$ of younger participants $(20.4 \%$ top 3$)\left[X^{2}(7)=21.75\right.$, $\mathrm{p}=0.003]$. More younger participants ranked Midnight as moderately harmful, with $52.3 \%$ ranking it as 4 th and 5 th most harmful compared to $11.3 \%$ of older participants. Attractiveness rankings of Turquoise (color) also differed by age, though distinct differences did not emerge $\left[X^{2}(9)=22.18, p=0.008\right]$. For example, $20.5 \%$ of older participants ranked Turquoise as most appealing versus $6.8 \%$ of young participants, but this pattern was the opposite for second-most appealing ( $20.5 \%$ younger vs $4.5 \%$ older).

\section{Sex}

Females more commonly ranked Pink (color) as most attractive ( $18.9 \%$ vs $0 \%)$ and top $3(39.6 \%$ vs $2.9 \%)$, while males more commonly ranked Pink as least attractive $(20.6 \%$ vs $5.7 \%)$ [ $\left.\chi^{2}(9)=26.55, p=0.002\right]$. A similar trend was observed for appeal rankings of Pink, though the stricter cutoff for statistical significance was not met $(\mathrm{p}=0.034)$.

\section{Race}

Harm perceptions of Smooth (taste) differed by race, with Non-White participants ranking Smooth as the least harmful more frequently than White participants $(35.5 \%$ vs $8.8 \%)\left[X^{2}(7)=29.43, p<0.001\right]$.

\section{Education}

Harm rankings of Rich (taste) differed by education, with participants with less education more commonly rating Rich as most harmful (17.6\% vs $1.9 \%)$ and less commonly ranking Rich in the middle position (26.5\% vs $51.9 \%$ ) compared to participants with more education $\left[\chi^{2}(8)=24.76, p=0.002\right]$.

\section{Nicotine Dependence}

Dependence scores influenced appeal rankings of Silver (color), as lower dependence participants were more likely to rank Silver as top 3 appealing than higher dependence participants $(32.7 \%$ vs
15.1\%) $\left[X^{2}(9)=25.25, p=0.003\right]$. Higher dependence participants were more likely to rank Silver as least appealing ( $18.2 \%$ vs $5.5 \%$ ), though this trend was opposite for second-least appealing (3.0\% vs $14.5 \%)$.

\section{DISCUSSION}

The current study assessed how different brand descriptors can influence perceptions of harm, attractiveness, and appeal, revealing three key findings. First, specific brand descriptors have varying degrees of influence on consumer perceptions of cigarette harm, attractiveness, and appeal. This finding was true regardless of the brand feature (i.e. prestige, taste, connotation, color). Some descriptors (e.g. Smooth) had favorable perceptions across all outcomes, while other descriptors (e.g. Red) had more negative perceptions. Second, perceptions of appeal were more strongly associated with perceptions of attractiveness than perceptions of harm. Third, demographic or baseline characteristics may influence perceptions of specific descriptors, indicating that the meaning of descriptors may change depending on the individual.

Perceptions of appeal were more strongly associated with perceptions of attractiveness than harm, which was observed overall and within each brand feature. For some brand features, such as color, perceptions of harm and appeal were not significantly correlated, and weak or no correlations existed between perceptions of harm and attractiveness. This finding suggests that attractiveness of a product is more closely related to intention to use more than the perceived health risks of that product, or that smokers do not make clear distinctions between product attractiveness and appeal. Survey research suggests that positive expectancies are strongly related to product appeal, but negative expectancies are $\operatorname{not}^{30}$. Additionally, experimental studies have found that anti-smoking advertisements focused on attractiveness (e.g. 'Smoking is gross!') increased negative perceptions of smokers among young adolescents ${ }^{31}$. Various media campaigns have aimed to reduce the appeal of cigarettes by using graphic images that induce disgust ${ }^{32-33}$.

Perceptions of specific descriptors observed in this study are consistent with previous research. White, which was ranked the least harmful color descriptor in the current study, has been found to be perceived as having lower tar and may be chosen over other 
colors by smokers concerned about health ${ }^{15}$. Red and Black color descriptors are perceived as being more harmful ${ }^{20}$, which was observed in this study. Turquoise was found to be the most appealing color in this study, which is consistent with industry documents suggesting that Blues are the most preferred pack color ${ }^{34}$. Smooth and Classic are particularly attractive descriptors to smokers ${ }^{26}$, with Smooth perceived as less harmful and having a smoother taste ${ }^{3,4}$. Similar results were observed in the current study, in which Smooth was ranked the most attractive and appealing taste descriptor and Classic was ranked the most appealing connotation descriptor. Thus, results of the current study are consistent with extant literature, though the current study is strengthened through the assessment of more brand descriptors than previous studies.

Research and tobacco industry documents indicate that perceptions of descriptors may be influenced by demographic or smoking characteristics of the individual ${ }^{26,35}$. For instance, we observed sex differences in attractiveness perceptions to the Pink color. Similar sex effects have been observed previously, with women giving more positive responses to a feminine brand name (April) and males giving more positive responses to a masculine brand name (Frontiersman) when smoking identical cigarettes ${ }^{36}$. Additional demographic factors, such as age, race, education, and nicotine dependence, were found to influence perceptions, though analyses were exploratory and were limited by a lack of a standard correction for multiple comparisons. However, most characteristics only influenced perceptions of individual descriptors (e.g. harm perceptions of Smooth differed by race) and systematic trends were not identified. Though menthol is not a descriptor, race and gender may moderate the association between menthol smoking and harm perceptions of own brand cigarettes $^{37}$. Future research should be designed specifically to measure differences in brand descriptor perceptions by demographic and other characteristics to determine whether certain descriptors produce misperceptions among smoker sub-groups.

\section{Limitations}

Certain study limitations demonstrate the need for continued research on this topic. It is possible that interviewer perceptions could have biased participant rankings, though we attempted to minimize bias by using a standardized discussion guide and encouraging participants to give honest opinions without reflecting on earlier responses and discussion. The current study assessed individual descriptors rather than combinations of descriptors. It is more likely that cigarette companies used multiple descriptors (e.g. color and connotation) to communicate branding rather than single descriptors in isolation. Thus, research on combinations of descriptors, such as in Hoek et al. ${ }^{26}$, may help understand the interaction effects of descriptors on perceptions and behavior. Additionally, the ranking task included a forced ranking, such that one descriptor had to be labeled most/least harmful, attractive, and appealing. Thus, the difference in perceptions between two descriptors may not be as large as it appears in this study. Another limitation is measurement of perceptions but not actual behavior, though appeal was chosen to measure intention to use. It remains unknown how the perceptions of harm, attractiveness, and appeal in the current study may translate into use and exposure. Future studies may include purchase tasks or measures of consumption to assess how descriptors influence cigarette purchasing and use behaviors, and how these behaviors affect exposure to harmful constituents.

\section{CONCLUSIONS}

As they have done in the past, cigarette manufacturers have adapted their branding strategies in response to marketing restrictions including the prohibition on misleading brand descriptors such as 'light' and 'mild'14,16. The current study observed that even after 'light' and 'mild' brand descriptors were prohibited from cigarette marketing, brand descriptors still influence perceptions of harm and intention to use, potentially as a result of newer brand descriptors and packaging colors ${ }^{3,12,14,26}$. It is important for the FDA to evaluate all brand descriptors for regulatory action. One consideration should be the use of plain packaging, which may have less appeal to adolescents ${ }^{38}$ and adult smokers ${ }^{39}$. Additionally, the FDA should use the lessons learned from cigarette branding when considering regulation of alternative products such as electronic cigarettes and heated tobacco products, novel products that use descriptors to convey information about flavor and other characteristics that can influence perceptions of harm and appeal ${ }^{40}$. 


\section{REFERENCES}

1. Cook BL, Wayne GF, Keithly L, Connolly G. One size does not fit all: how the tobacco industry has altered cigarette design to target consumer groups with specific psychological and psychosocial needs. Addiction. 2003;98(11):15471561. doi:10.1046/j.1360-0443.2003.00563.x

2. Wakefield M, Morley C, Horan JK, Cummings KM. The cigarette pack as image: new evidence from tobacco industry documents. Tob Control. 2002;11(Suppl 1):i73-i80. doi:10.1136/tc.11.suppl_1.i73

3. Bansal-Travers M, Hammond D, Smith P, Cummings, KM. The impact of cigarette pack design, descriptors, and warning labels on risk perception in the U.S. Am J Prev Med. 2011;40(6):674-682. doi:10.1016/j.amepre.2011.01.021

4. Hammond D, Dockrell M, Arnott D, Lee A, McNeill A. Cigarette pack design and perceptions of risk among UK adults and youth. Eur J Public Health. 2009;19(6):631637. doi:10.1093/eurpub/ckp122

5. Hammond D, Parkinson C. The impact of cigarette package design on perceptions of risk. J Public Health. 2009;31(3):345-353. doi:10.1093/pubmed/fdp066

6. White V, Williams T, Wakefield M. Has the introduction of plain packaging with larger graphic health warnings changed adolescents' perceptions of cigarette packs and brands?. Tob Control. 2015;24(Suppl 2):ii42-ii49. doi:10.1136/tobaccocontrol-2014-052084

7. National Cancer Institute. The FTC Cigarette Test Method for Determining Tar, Nicotine, and Carbon Monoxide Yields of U.S. Cigarettes. Report of the NCI Expert Committee. In: Tobacco Control Monograph No. 7. Bethesda, MD: U.S. Department of Health and Human Services, National Institutes of Health, National Cancer Institute; 1996. https://cancercontrol.cancer.gov/sites/ default/files/2020-08/m07_complete.pdf. Accessed November 24, 2020.

8. U.S. Department of Health and Human Services. Reducing Tobacco Use: A Report of the Surgeon General. Atlanta, Georgia: U.S. Department of Health and Human Services, Centers for Disease Control and Prevention, National Center for Chronic Disease Prevention and Health Promotion, Office on Smoking and Health; 2000. https://www.cdc.gov/tobacco/data_statistics/sgr/2000/ complete_report/pdfs/fullreport.pdf. Accessed November 24, 2020.

9. Borland R, Fong GT, Yong HH, et al. What happened to smokers' beliefs about light cigarettes when "light/ mild" brand descriptors were banned in the UK? Findings from the International Tobacco Control (ITC) Four Country Survey. Tob Control. 2008;17(4):256-262. doi:10.1136/tc.2007.023812

10. Yong HH, Borland R, Cummings KM, et al. Impact of the removal of misleading terms on cigarette pack smokers' beliefs about Light/Mild cigarettes: Cross-country comparisons. Addiction. 2011;106(12):2204-2213. doi:10.1111/j.1360-0443.2011.03533.x
11. Yong HH, Borland R, Cummings KM, et al. US smokers' beliefs, experiences, and perceptions of different cigarette variants before and after the FSPTCA ban on misleading descriptors such as "light," "mild," or "low". Nicotine Tob Res. 2016;18(11):2115-2123. doi:10.1093/ntr/ntw107

12. Mercincavage M, Albedla B, Mays D, Souprountchouk V, Giovenco DP, Audrain-McGovern J, Strasser AA. Shedding 'light' on cigarette pack design: colour differences in product perceptions, use and exposure following the US descriptor ban. Tob Control. 2020. doi:10.1136/tobaccocontrol-2020-055886

13. Carroll DM, Stepanov I, O'Connor R, et al. Impact of cigarette filter ventilation on U.S. smokers' perceptions and biomarkers of exposure and potential harm. Cancer Epidemiol Biomarkers Prev. 2020;30(1):38-44. doi:10.1158/1055-9965.EPI-20-0852

14. Alpert HR, Carpenter D, Connolly GN. Tobacco industry response to a ban on lights descriptors on cigarette packaging and population outcomes. Tob Control. 2018;27:390-398. doi:10.1136/tobaccocontrol-2017-053683

15. Bansal-Travers M, O'Connor R, Fix BV, Cummings KM. What do cigarette pack colors communicate to smokers in the U.S.?. Am J Prev Med. 2011;40(6):683-689. doi:10.1016/j.amepre.2011.01.019

16. Connolly GN, Alpert HR. Has the tobacco industry evaded the FDA's ban on 'Light' cigarette descriptors?. Tob Control. 2014:23(2):140-145. doi:10.1136/tobaccocontrol-2012-050746

17. Falcone M, Bansal-Travers M, Sanborn PM, Tang KZ, Strasser AA. Awareness of FDA-mandated cigarette packaging changes among smokers of 'light' cigarettes. Health Educ Res. 2015;30(1):81-86. doi:10.1093/her/cyu070

18. King B, Borland R. What was "light" and "mild" is now "smooth" and "fine": New labelling of Australian cigarettes. Tob Control. 2005;14(3):214-215. doi:10.1136/tc.2005.011692

19. Elton-Marshall T, Fong GT, Zanna MP, et al. Beliefs about the relative harm of "light" and "low tar" cigarettes: findings from the International Tobacco Control (ITC) China Survey. Tob Control. 2010;19(Suppl 2):i54-i62. doi:10.1136/tc.2008.029025

20. Mutti S, Hammond D, Borland R, Cummings KM, O’Connor RJ, Fong GT. Beyond light \& mild: Cigarette brand descriptors and perceptions of risk in the International Tobacco Control (ITC) Four Country Survey. Addiction. 2011;106(6):11661175. doi:10.1111/j.1360-0443.2011.03402.x

21. Skaczkowski G, Durkin S, Kashima Y, Wakefield M. Influence of premium vs masked cigarette brand names on the experienced taste of a cigarette after tobacco plain packaging in Australia: an experimental study. BMC Public Health. 2018;18(1):295. doi:10.1186/s12889-018-5200-8

22. Lempert LK, Glantz S. Packaging colour research by tobacco companies: the pack as a product characteristic. Tob Control. 2017;26(3):307-315. doi:10.1136/tobaccocontrol-2015-052656

23. RJ Reynolds, Etzel EC. Camel Filter revised packaging test: Consumer research proposal. Bates No. 500566627/6632. 
1979. https://www.industrydocuments.ucsf.edu/tobacco/ docs/\#id=pjdf0099. Accessed November 24, 2020.

24. Philip Morris USA, Isaacs J. Identified HTI test of Marlboro Ultra Lights in a blue pack versus Malboro Ultra Lights in a red pack (Project No. 1256/1257). Bates No. 2047387079/7089. 1981. https://www. industrydocuments.ucsf.edu/tobacco/docs/\#id=nkxj0114. Accessed November 24, 2020.

25. Rees VW, Kreslake JM, Cummings KM, et al. Assessing consumer responses to PREPs: A review of tobacco industry and independent research methods. Cancer Epidemiol Biomarkers Prev. 2009;18(12):3225-3240. doi:10.1158/1055-9965.EPI-09-0946

26. Hoek J, Gendall P, Eckert C, Kemper J, Louviere J. Effects of brand variants on smoker's choice behaviours and risk perceptions. Tob Control. 2015;25(2):160-165. doi:10.1136/tobaccocontrol-2014-052094

27. U. S. Government. Family Smoking Prevention and Tobacco Control and Federal Retirement Reform. Public Law 111-31-2009. https://www.govinfo.gov/content/ pkg/PLAW-111publ31/pdf/PLAW-111publ31.pdf. Accessed November 24, 2020.

28. Heatherton TF, Kozlowski LT, Frecker RG, Fagerström KO. The Fagerström Test of Nicotine Dependence: a revision of the Fagerström Tolerance Questionnaire. Br J Addict. 1991;86(9):1119-1127. doi:10.1111/j.1360-0443.1991.tb01879.x

29. Glover ED, Nilsson F, Westin A, Glover PN, Laflin MT, Persson B. Developmental history of the Glover-Nilsson smoking behavioral questionnaire. Am J Health Behav. 2005;29(5):443-455. doi:10.5555/ajhb.2005.29.5.443

30. O'Connor RJ, Ashare RL, Fix BV, Hawk LW Jr, Cummings KM, Schmidt WC. College students' expectancies for light cigarettes and potential reduced exposure products. Am J Health Behav. 2007;31(4):402-410. doi:10.5993/AJHB.31.4.7

31. Pechmann C, Ratneshwar S. The effects of antismoking and cigarette advertising on young adolescents' perceptions of peers who smoke. J Consum Res. 1994;21(2):236-251. doi:10.1086/209395

32. Pechmann G, Reibling ET. Antismoking advertisements for youths: An independent evaluation of health, counterindustry, and industry approaches. Am J Public Health. 2006;96(5):906-913. doi:10.2105/AJPH.2004.057273

33. National Cancer Institute. The Role of the Media in Promoting and Reducing Tobacco Use. In: Tobacco Control Monograph No. 19. Bethesda, MD: U.S. Department of Health and Human Services, National Institutes of Health, National Cancer Institute; 2008. https://cancercontrol.cancer.gov/brp/tcrb/monographs/ monograph-19. Accessed November 24, 2020.

34. Philip Morris USA, Lalley K, Eisen K, Bonhomme J. Marketing Research Department Report: Marlboro Ultra Lights Qualitative Research. Bates No. 20408025202040802523. 1988. https://www.industrydocuments. ucsf.edu/tobacco/docs/\#id=hkhg0127. Accessed November 24, 2020.

35. Philip Morris USA, Halpern M. Interoffice correspondence: Literature Review--Color. 1994:2-25. https://www. industrydocuments.ucsf.edu/tobacco/docs/\#id=ylvk0191. Accessed November 24, 2020.

36. Friedman HH, Dipple WS Jr. The effect of masculine and feminine brand names on the perceived taste of a cigarette. Decis Sci. 1978;9(3):467-471. doi:10.1111/j.1540-5915.1978.tb00735.x

37. Cohn AM, Rose SW, Ilakkuvan V, et al. Harm perceptions of menthol and nonmenthol cigarettes differ by brand, race/ethnicity, and gender in US adult smokers: results from PATH Wave 1. Nicotine Tob Res. 2019;21(4):439449. doi:10.1093/ntr/ntx277

38. Germain D, Wakefield MA, Durkin SJ. Adolescents' perceptions of cigarette brand image: Does plain packaging make a difference?. J Adolesc Health. 2010;46(4):P385-P392. doi:10.1016/j.jadohealth.2009.08.009

39. Wakefield MA, Germani D, Durkin SJ. How does increasingly plainer cigarette packaging influence adult smokers' perceptions about brand image?. An experimental study. Tob Control. 2008;17(6):416-421. doi:10.1136/tc.2008.026732

40. Ford A, MacKintosh AM, Bauld L, Moodie C, Hastings G. Adolescents' responses to the promotion and flavouring of e-cigarettes. Int J Public Health. 2016;61:215-224. doi:10.1007/s00038-015-0769-5

\section{CONFLICTS OF INTEREST}

The authors have each completed and submitted an ICMJE form for disclosure of potential conflicts of interest. The authors declare that they have no competing interests, financial or otherwise, related to the current work. All authors report grants from National Cancer Institute (P01CA217806) during the conduct of the study. K. M. Cummings reports grants from National Cancer Institute (P01CA200512) outside the submitted work, and payment as a consultant to Pfizer Inc., for service on an external advisory panel to assess ways to improve smoking cessation delivery in healthcare settings. M. Bansal-Travers reports personal fees from CDC, personal fees from University of Arkansas Medical Sciences, and other fees from Westat, outside the submitted work. R. J. O'Connor reports personal fees from World Health Organization, grants and personal fees from Food and Drug Administration, personal fees from University of South Carolina, personal fees from Georgetown University, grants and personal fees from National Institutes of Health, outside the submitted work. V. W. Rees reports personal fees from Expert testimony in tobacco litigation, outside the submitted work. Finally, K. M. Cummings and V. W. Rees have served as paid expert witnesses in litigation filed against the tobacco industry.

\section{FUNDING}

This work was supported by the National Cancer Institute (P01CA217806).

\section{PROVENANCE AND PEER REVIEW}

Not commissioned; externally peer reviewed. 